DOI: $10.17516 / 1999-494 X-0147$

УДК 539.4:621.873

\title{
Research of Strength, Service Life and Reliability of Crane Metal Structures: Overview and Results
}

\author{
Lyudmila F. Moskvicheva ${ }^{a}$ and Natalya A. Chernyakova*b \\ ${ }^{a}$ Siberian Federal University \\ Krasnoyarsk, Russian Federation \\ ${ }^{b}$ Federal Research Center for Information \\ and Computational Technologies Krasnoyarsk branch \\ Krasnoyarsk, Russian Federation
}

Received 09.11.2020, received in revised form 15.11.2020, accepted 28.11.2020

Abstract. The results of research and a development retrospective of the regulatory framework for the design and calculation of crane metal structures are presented. The cause-and-effect complex of bridge crane failures is considered, as well as research directions within the framework of the computational and experimental complex in the field of strength, reliability, dynamics, and analysis of the stressstrain state of fatigue strength are analyzed. The results of experimental fatigue studies of samples and models of crane structures are presented. The methodology of calculations for crack resistance and reliability is given on the example of the support unit of the end beam of a bridge crane.

Keywords: bridge cranes, methodology of calculations for crack resistance and reliability, analysis of stress-strain state and fatigue strength.

Citation: Moskvicheva L.F., Chernyakova N.A. Research of strength, service life and reliability of crane metal structures: overview and results, J. Sib. Fed. Univ. Eng. \& Technol., 2020, 13(8), 933-955. DOI: 10.17516/1999-494X-0147

(C) Siberian Federal University. All rights reserved

This work is licensed under a Creative Commons Attribution-Non Commercial 4.0 International License (CC BY-NC 4.0).

* Corresponding author E-mail address: fortuna@ict.nsc.ru 


\title{
Исследования прочности, ресурса
}

\section{и надежности крановых металлоконструкций: обзор и результаты}

\author{
Л.Ф. Москвичева ${ }^{a}$, Н.А. Чернякова ${ }^{0}$ \\ ${ }^{a}$ Сибирский федеральный университет \\ Российская Федераиия, Красноярск \\ ${ }^{6}$ Федеральный исследовательский иентр информационных \\ и вычислительных технологий Красноярский филиал \\ Российская Федерачия, Красноярск
}

Аннотация. Представлены результаты исследований и ретроспектива развития нормативной базы проектирования и расчетов крановых металлоконструкций. Рассмотрен причинноследственный комплекс отказов мостовых кранов, направления исследований в рамках расчетно-экспериментального комплекса в области прочности, надежности, динамики, анализа напряженно-деформированного состояния и усталостной прочности. Приведены результаты экспериментальных исследований образцов и моделей крановых конструкций на усталость. Методология расчетов на трещиностойкость и надежность представлена на примере опорного узла концевой балки мостового крана.

Ключевые слова: мостовые краны, методология расчетов на трещиностойкость и надежность, анализ напряженно-деформированного состояния и усталостной прочности.

Цитирование: Москвичева, Л.Ф. Исследования прочности, ресурса и надежности крановых металлоконструкций: обзор и результаты / Л.Ф. Москвичева, Н.А. Чернякова // Журн. Сиб. федер. ун-та. Техника и технологии, 2020. 13(8). C. 933-955. DOI: 10.17516/1999-494X-0147

\section{Введение}

Крановые конструкции подъемно-транспортных машин (ПТМ) являются одним из наиболее распространенных типов промышленного оборудования. Исследованиям вопросов прочности, надежности и живучести крановых металлоконструкций (КМК) традиционно придавали огромное значение, учитывая потенциальную опасность ПТМ в эксплуатации, уникальность конструктивных решений и сложные режимы нагружения в интенсивных технологических процессах разных производств.

Описания конструкций кранов различного назначения даны в [1-4], общие вопросы проектирования и расчетов освещены в $[1,2,5,6]$, вопросы динамики и нагруженности подъемно-транспортных машин рассматривались в $[7,8]$, анализ отказов и показателей надежности выполнялся в $[9,10]$, вопросы безопасной эксплуатации и ремонта отражены в $[10,11]$, особенности производства и влияние технологических факторов на несущую способность крановых конструкций изложены в $[11,12]$.

\section{1. Ретроспектива исследований}

и развитие нормативной базы проектирования и расчетов

Одним из первых документов, регламентирующих расчеты крановых конструкций на стадии проектирования, является документ инспекции котлонадзора «Основные данные по проек- 
тированию и расчету кранов» (1943 г.). Принятый метод расчета крановых мостов заключался в том, что пространственная система расчленялась на несколько плоских систем и каждая балка или ферма рассчитывалась на нагрузки, действующие в ее плоскости. Данное предположение не учитывает взаимодействия отдельных узлов пространственной системы между собой, что приводит к завышению запасов прочности. Более точные методы расчета, базирующиеся на использовании канонических уравнений метода сил для определения усилий и перемещений, были предложены в $[13,14]$. Следующим важным этапом стала подготовка специалистами ВНИИПТМАШ «Технических условий на проектирование мостовых электрических кранов» (1957 г.), основанных на методе расчетов по допускаемым напряжениям.

В последующий период (1960-1980-е гг.) вопросам теории проектирования и расчетов крановых конструкций уделялось значительное внимание [3, 5, 6, 9, 15]. В ЦНИИпроектстальконструкции были разработаны «Указания по проектированию стальных конструкций крановперегружателей» (1962 г.) и «Временные технические условия на проектирование стальных конструкций судостроительных козловых кранов г/п 300-1000 т» (1972 г.), согласно которым расчеты КМК впервые выполнялись по методу предельных состояний. Данный метод вошел в практику проектирования мостовых кранов общего назначения (ВНИИПТМАШ), мостовых перегружателей и козловых кранов (ЦНИИПСК), башенных кранов (ВНИИстройдормаш). В 1960-е гг. институтом ВНИИПТМАШ были начаты разработки «Единых норм и технических условий на проектирование, расчет и изготовление крановых металлоконструкций», что привело к созданию в системе Минтяжмаша СССР целой серии руководящих технических материалов (РТМ), в основу которых положен метод предельных состояний. РТМ регламентировали общие указания по расчетам, методы расчета крановых механизмов, узлов, деталей и типовых элементов стальных конструкций, нормы расчета отдельных типов кранов.

Обобщение результатов исследований, опыта проектирования и производства кранов различного назначения нашло отражение в специальной справочной литературе [2]. Основным нормативным документом, регламентирующим расчеты металлоконструкций мостовых кранов повышенной грузоподъемности, является РТМ 24.190.07-85 «Нормы расчета стальных конструкций мостовых кранов грузоподъемностью свыше 50 т» [16]. Металлоконструкции кранов для атомных станций, отличающиеся повышенным уровнем ответственности, рассчитываются согласно требованиям $[17,18]$. Основным методом расчета МК, элементов и соединений является метод предельных состояний, в соответствии с которым обеспечиваются условия прочности, устойчивости, жесткости и выносливости. Анализ эксплуатационных повреждений, отказов и разрушений крановых конструкций $[9,10,19]$ позволяет выделить следующие предельные состояния:

I - нарушение прочности или устойчивости элементов конструкций при действии максимальных нагрузок;

II - нарушение нормальной эксплуатации вследствие появления усталостных трещин в элементах металлоконструкций;

III - возникновение деформаций, препятствующих нормальной эксплуатации крана [20].

В качестве расчетных характеристик по предельному состоянию I используются максималь-

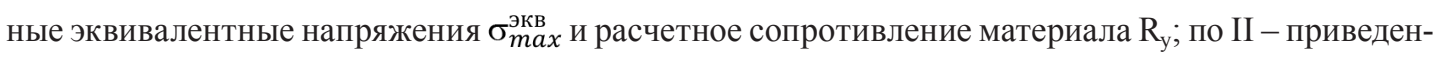
ные (эквивалентные) циклические напряжения $\sigma_{\text {пр }}$ и расчетное сопротивление усталости $\mathrm{R}_{\mathrm{v}}$; по III - максимальные упругие перемещения $\mathrm{f}_{\max }$ и предельные допустимые перемещения [f]:

$$
-935-
$$




$$
\mathrm{I} \sigma_{\max }^{\text {экв }} \leq R_{y} \gamma_{c} ; \mathrm{II} \sigma_{\text {пр }} \leq R_{v} \gamma_{c} ; \mathrm{III} f_{\max } \leq[\mathrm{f}]
$$

где $\gamma_{\mathrm{c}}$ - коэффициент условий работы.

Наиболее опасно с точки зрения возможной аварии или катастрофического обрушения второе предельное состояние, связанное с наличием технологических дефектов и развитием эксплуатационных трещин:

- наступление разрушения типа хрупкого, квазихрупкого или вязкого с инициацией процесса от технологического дефекта или усталостной трещины при действии максимальных рабочих нагрузок, возникновении перегрузок в аварийном режиме работы или нерасчетных динамических нагрузок;

- образование и развитие трещин малоцикловой усталости от повторных нагрузок, особенно в зонах концентрации напряжений, или трещин многоцикловой усталости от вибрационных нагрузок с большим числом циклов нагружения.

Нормативные расчеты по условиям (1) проводятся без учета наличия макродефектов в элементах конструкций (ЭК), при этом устанавливаются основные геометрические размеры, выбираются материалы, регламентируется уровень нагруженности. С учетом возможности образования и развития в элементах конструкций на стадии изготовления, монтажа и эксплуатации дефектов типа трещин нормативные расчеты должны быть дополнены поверочными расчетами на трещиностойкость и надежность, что имеет особо важное значение для анализа предельного состояния II. В рассмотрение должны быть введены дополнительные типы предельных состояний, отражающие наличие и развитие в конструкциях технологических дефектов и эксплуатационных трещин для статического и циклического нагружения. Проведение данных расчетов базируется на критериях механики разрушения и теории надежности механических систем.

В качестве основных критериев хрупкого, квазихрупкого и вязкого разрушений применительно к крановым конструкциям целесообразно использовать критические значения напряжений $\left(\sigma_{c}\right)$, коэффициентов интенсивности напряжений $\left(\mathrm{K}_{\mathrm{c}}, \mathrm{K}_{\mathrm{Ic}}\right)$, описывающих напряженно-деформированное состояние в вершине трещины, и J-интеграла $\left(\mathrm{J}_{\mathrm{c}}\right)$, характеризующего энергетические затраты, связанные с образованием новых поверхностей разрушения. Данные характеристики для сталей, применяемых в краностроении, исследованы в [21-24].

\section{2. Причинно-следственный комплекс отказов}

Практика эксплуатации кранов характеризуется случаями многочисленных разрушений несущих элементов, связанных с возникновением усталостных трещин в растянутых элементах конструкции после 15-20 лет эксплуатации. Обследование крановых конструкций после аварии позволяет установить множественные зоны повреждений и трещинообразования, при этом, как правило, только в одной из них происходит развитие магистральных трещин, которые приводят к тяжелой аварии всей конструкции. Вместе с тем иногда усталостные разрушения возникают через 2-3 года эксплуатации в результате проявления динамических эффектов (резонансные явления в МК и удары на стыках рельсов).

В качестве основных причин отказов и аварий указывают: несоответствие химического состава и механических свойств металла техническим требованиям; усталостные трещины; длительная эксплуатация без проведения диагностирования; низкие температуры эксплуатации; конструктив-

$$
-936-
$$


ные концентраторы напряжений; технологические дефекты в соединениях и основном металле. Анализ механизмов и условий развития трещин, номинального и локального НДС в областях и элементах МК, содержащих усталостные трещины, позволяет сделать следующие выводы:

- развитие большинства усталостных трещин реализуется по модели нормального отрыва (до $80 \%$ трещин);

- характерным является возникновение сквозных трещин, не приводящих к внезапному разрушению МК, при этом их размеры могут достигать 100...500 мм;

- до $25 . .30$ \% усталостных трещин возникает от технологических дефектов сварки (подрез, непровар) с развитием первоначально по зоне термического влияния и последующим выходом в основной металл.

В качестве общих характеристик надежности крановых конструкций рассмотрим результаты обработки эксплуатационных наблюдений за отказами мостового крана за семилетний период (табл. 1). Число отказов механического оборудования составляет 40 \% от общего числа. Средняя наработка на отказ механического оборудования превышает аналогичный показатель электрооборудования в 1,62 раза, т.е. мехоборудование надежнее с точки зрения безотказности, но с точки зрения ремонтопригодности уступает электрооборудованию (среднее время восстановления для электрооборудования составляет 0,46 такового для мехоборудования). Значительная асимметрия распределений наработки на отказ и тот факт, что среднее значение мало отличается от среднеквадратического отклонения, позволяют принять гипотезу экспоненциального распределения. На рис. 1 показаны функции надежности крана и его основных подсистем.

Таблица 1. Основные показатели надежности крана

Table 1. The main reliability indices of the crane

\begin{tabular}{|l|c|c|c|}
\hline \multicolumn{1}{|c|}{ Показатель } & $\begin{array}{c}\text { Механическое } \\
\text { оборудование }\end{array}$ & Электрооборудование & Кран в целом \\
\hline Число отказов & 104 & 160 & 264 \\
\hline Средняя наработка на отказ, сут & 26,90 & 16,59 & 10,36 \\
\hline $\begin{array}{l}\text { Среднеквадратическое отклонение } \\
\text { наработки на отказ, сут }\end{array}$ & 24,87 & 17,96 & 9,66 \\
\hline Среднее время восстановления, ч & 1,41 & 0,65 & 0,94 \\
\hline
\end{tabular}

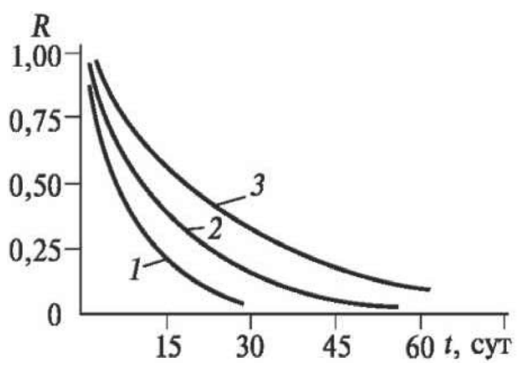

Рис. 1. Функции надежности мостового крана (1), электрооборудования (2) и механического оборудования (3)

Fig. 1. Reliability functions for bridge cranes (1), electrical equipment (2), and mechanical equipment (3) 
Необходимо отметить, что, несмотря на периодическое повторение типичных аварий, известные систематические причины, аварийность подъемно-транспортных машин не снижается.

\section{3. Расчетно-экспериментальный комплекс. \\ Направления исследований}

В последние десятилетия интенсивные научные исследования в области прочности и надежности крановых металлоконструкций ведутся в следующих направлениях:

- исследование закономерностей формирования надежности крановых МК и оценка показателей надежности по данным эксплуатации;

- экспериментальные и численные исследования динамики конструкций и определение действительных уровней нагруженности;

- расчетные и экспериментальные исследования напряженно-деформированного состояния (НДС);

- исследование закономерностей усталостного и хрупкого разрушения крановых МК и совершенствование методов расчета на выносливость и трещиностойкость.

Исследования надежности выполняются преимущественно в двух областях:

- сбор и обработка статистической информации по отказам конструкций и их элементов, оценка и анализ количественных показателей надежности;

- обобщение статистических исследований надежности, переход к вероятностным представлениям результатов, формулировка комплексных показателей надежности.

Исследования в области динамики крановых конструкций делятся на следующие взаимосвязанные направления:

- численное моделирование процессов динамики на ЭВМ;

- обоснование и оптимизация динамических коэффициентов;

- определение действующих нагрузок с учетом динамических процессов;

- разработка методов снижения вибрации и колебаний.

Традиционные, применяющиеся до сих пор, методы учета динамических нагрузок предполагают увеличение действующих номинальных статических нагрузок и напряжений путем применения динамических коэффициентов. Вопросам определения значений коэффициентов для различных типов кранов и режимов работы было уделено значительное внимание (ВНИИПТМАШ). В последние десятилетия при проведении динамических расчетов наметилась тенденция использования фактических значений динамических нагрузок, определение которых достаточно сложная задача. Здесь обычно рассматривают переходные режимы пуска-торможения [7, 8, 25-27], а также случаи наезда крана на жесткое препятствие. Для определения реальных нагрузок разрабатывают многомассовые модели, описываемые системами дифференциальных уравнений, в результате решения которых определяют динамические характеристики МК и делают выводы о допускаемой нагруженности.

Расчетные и экспериментальные исследования НДС развиваются в следующих направлениях:

- экспериментальные исследования НДС элементов натурных крановых МК или их моделей;

- расчетный анализ распределения напряжений в ЭК с использованием методов сопротивления материалов, строительной механики, теории упругости и численного моделирования на ЭВМ;

$$
-938-
$$


- обобщение расчетных и экспериментальных исследований НДС и разработка методов и алгоритмов расчета крановых МК.

Обычно исследования НДС выполняются для ЭК, при эксплуатации которых наблюдаются систематические возникновения трещин и разрушения, и для вновь проектируемых ЭК. Одним из наиболее часто исследуемых ЭК является высоконагруженный опорный узел концевой балки [28, 29], причем экспериментальные исследования натурных МК [29] показали, что величины напряжений от статических нагрузок в надбуксовом сечении невелики и не влияют на его прочность. Ряд исследований посвящен определению НДС балок крановых мостов. В [30] было выполнено тензометрирование элементов МК моста, которое показало, что расчетные методы не учитывают пространственную работу МК моста, в связи с чем главная балка имеет завышенные запасы прочности. С целью определения возможности повышения несущей способности предложено учитывать наличие нерасчетных элементов (рельсы, ребра, настил балкона).

Напряженно-деформированное состояние МК балок крановых мостов определяется преимущественно геометрическими характеристиками сечений балок и внешними нагрузками, основные из которых - нагрузки на мост со стороны грузовых тележек. В [31] экспериментально исследовано распределение давления колес тележки на балки моста. Построены осциллограммы давлений колес, исследовано влияние местного давления ходового колеса грузовой тележки на напряжения в верхнем поясе главной балки моста. Данные исследования вызваны появлением трещин в верхнем поясе вдоль главных балок мостов под рельсом, что объясняется неравномерностью распределения давления между колесами тележки.

В 1970-х гг. был выполнен ряд экспериментальных исследований других несущих МК. Тензометрирование крановых ферм позволило установить, что теоретические расчетные напряжения в значительной мере отличаются от экспериментальных. Были исследованы модели стрелы плавучего крана, НДС и устойчивость ригелей козловых кранов и перегружателей, при этом в задачи исследований входило: определение начальных несовершенств - искривлений плоских элементов и остаточных сварочных напряжений, образовавшихся при изготовлении фрагментов; выявление действительного НДС; выявление предельного состояния фрагментов ригелей по местной устойчивости стенок; анализ и сравнение данных эксперимента с данными расчетов по нормам проектирования.

Расчетный анализ НДС крановых МК преимущественно проводили для балок моста как наиболее нагруженных и металлоемких конструкций. Основы расчета пространственных крановых мостов заложены в [13]. Отмечается, что традиционные методы расчета крановых мостов не учитывают пространственной связи моста и отдельные фермы или балки рассчитываются как плоские конструкции, что не отражает действительной работы моста. В [32] выполнен расчет на поперечный изгиб крановых коробчатых балок, показавший, что при поперечном изгибе коробчатых балок в сечениях возникают нелинейные распределения напряжений. Оценка несущей способности пролетных балок, выполненная по приближенной методике ВНИИПТМАШ в [33], позволила выявить типоразмеры балок, в которых возможно снижение металлоемкости. В [31] анализировали местные напряжения в верхнем поясе крановой коробчатой балки с рельсом посередине. Установлено, что возникновение продольных усталостных трещин в верхнем поясе связано с местным влиянием давления ходового колеса тележки, которое передается через рельс на верхний пояс и вызывает его изгиб в своей плоскости. Выполня- 
лись также исследования НДС поперечных сечений крановых мостов и диафрагм коробчатых крановых балок.

Ряд исследований посвящен расчетам НДС МК крановых тележек с учетом пространственной работы МК и условий их опирания. Разработанная методика расчета ВНИИПТМАШ позволяет определять расчетные напряжения в раме тележки, состоящей из тонкостенных профилей открытого и закрытого типов. Предложен приближенный метод расчета рам крановых тележек, достаточно точно отражающий их действительную работу, и новая методика, учитывающая влияние на элементы рамы скручивающих моментов.

Результаты экспериментальных и расчетных исследований НДС позволили уточнить методики расчета отдельных элементов крановых МК, оценить корректность применения стержневых моделей, учитывающих жесткость крепления элементов и их пространственную работу, разработать методики проектных расчетов, позволяющих оптимизировать весовые показатели МК, выявить области рационального применения мостов различных типов (коробчатые, двутавровые, ферменные).

Исследования усталостной прочности крановых металлоконструкций наиболее интенсивно проводили в 1970-1980-е гг. на основе сформировавшихся к этому времени теорий усталостной прочности $[34,35]$ с отражением специфических особенностей, характерных для МК подъемно-транспортного оборудования, по следующим направлениям:

- усталостные испытания образцов, моделей и натурных элементов крановых МК для определения пределов выносливости и оценки влияния конструктивно-технологических факторов;

- расчетно-экспериментальное определение пределов выносливости элементов крановых МК и развитие общей методики расчета на усталостную прочность.

В этих направлениях были получены важные практические результаты, что позволило создать нормативную базу расчетов мостовых кранов на выносливость [36, 37].

Важные исследования были выполнены по расчетному определению пределов выносливости элементов крановых МК. В общем виде сформулирована методика расчетного определения пределов выносливости для МК из малоуглеродистых и низколегированных сталей, включая теоретическое определение влияния масштабного фактора на выносливость сварных соединений и величину эффективных коэффициентов концентрации с учетом степени конструктивно-технологического подобия моделей и узлов натурных конструкций. Разработанные методы расчетного определения пределов выносливости элементов крановых МК при стационарном режиме нагружения основаны на использовании схематизированной диаграммы предельных напряжений и приведении истинных напряжений около концентратора к эквивалентным равномерно распределенным напряжениям растяжения-сжатия. Такой подход позволяет учитывать основные конструктивно-технологические факторы. Вследствие большого разнообразия сварных соединений в крановых МК, трудоемкости теоретического и экспериментального определения коэффициентов концентрации напряжений была разработана единая инженерная расчетная схема и алгоритм вычисления коэффициентов концентрации напряжений, что позволило выполнить расчет теоретических коэффициентов концентрации напряжений в типовых сварных соединениях. Кроме того, были проведены экспериментальные исследования влияния асимметрии циклов напряжений, рассмотрена возможность учета динамических колебательных циклов, влияние перегрузок, нестационарность нагружения.

$$
-940-
$$


Данные исследования позволили обосновать линейный закон накопления усталостных повреждений.

Вероятностные методы расчета в последние годы стали получать все большее развитие и практические приложения в основном в двух направлениях: расчеты показателей надежности [9, $22,37,38]$ и вероятностные расчеты пределов выносливости сварных соединений. Во втором случае обычно используются детерминированные расчеты, гипотеза слабого звена и метод МонтеКарло. Были выполнены численные исследования зависимостей статистических оценок пределов выносливости соединений от вариаций средних величин и дисперсий таких параметров сварных швов, как катеты, высота наплавленного металла, радиус перехода металла шва к основному металлу, глубина подрезов и сварочные остаточные напряжения в околошовной зоне.

\section{4. Экспериментальные исследования крановых металлоконструкций}

Экспериментальные исследования крановых металлоконструкций проводятся по трем основным направлениям:

- определение характеристик механических свойств и трещиностойкости сталей и сварных соединений, испытания элементов конструкций;

- модельные исследования МК;

- натурные исследования и обследования МК (рис. 2).

Проводятся испытания образцов, моделей, отдельных элементов МК и экспериментальные исследования на натурных объектах. При исследованиях напряженно-деформированных состояний и фактических режимов работы кранов предпочтение отдают испытаниям на натурных объектах. Формирование базы данных расчетных параметров требует значительного объема экспериментальных исследований характеристик прочности, пластичности, усталостной прочности и трещиностойкости при статическом и циклическом нагружениях.

Наиболее трудоемкими являются испытания на усталость и трещиностойкость, и в то же время им уделяется наибольшее внимание в связи с ограниченностью данных в нормативносправочной литературе. В ряде случаев испытания на усталость и трещиностойкость проводили при обосновании конструкторско-технологических решений, анализе причин усталостных и хрупких разрушений МК. Примером таких испытаний могут служить сравнительные испытания на усталость образцов с отверстиями (рис. 3).

Испытания проводили для выяснения причин аварии перегружателя трубчато-балочной конструкции после девяти лет эксплуатации, произошедшей в результате обрушения рабочей консоли. Причина - развитие усталостных трещин длиной 630 и 1100 мм, инициированных от отверстий диаметром 400 мм для прокладки кабельных коммуникаций. Отверстия имели усиления в виде привариваемого кольца окантовки шириной 200 мм и толщиной 14 мм.

Испытывали модельные образцы из стали 09Г2С с диаметром отверстия 60 мм трех партий: 1 - без окантовки; 2 - окантовка кольцом из трубы 60 х 3,5 мм с двухсторонней сваркой без разделки кромок; 3 - аналогично второй партии, но с недоваром на одну четверть периметра отверстия (имитация технологического дефекта).

Соответствующие кривые усталости, полученные для стадии разрушения при коэффициенте асимметрии $\mathrm{R}=0,3$, показаны на рис. 4. Снижение разрушающих амплитуд напряжений

$$
-941-
$$




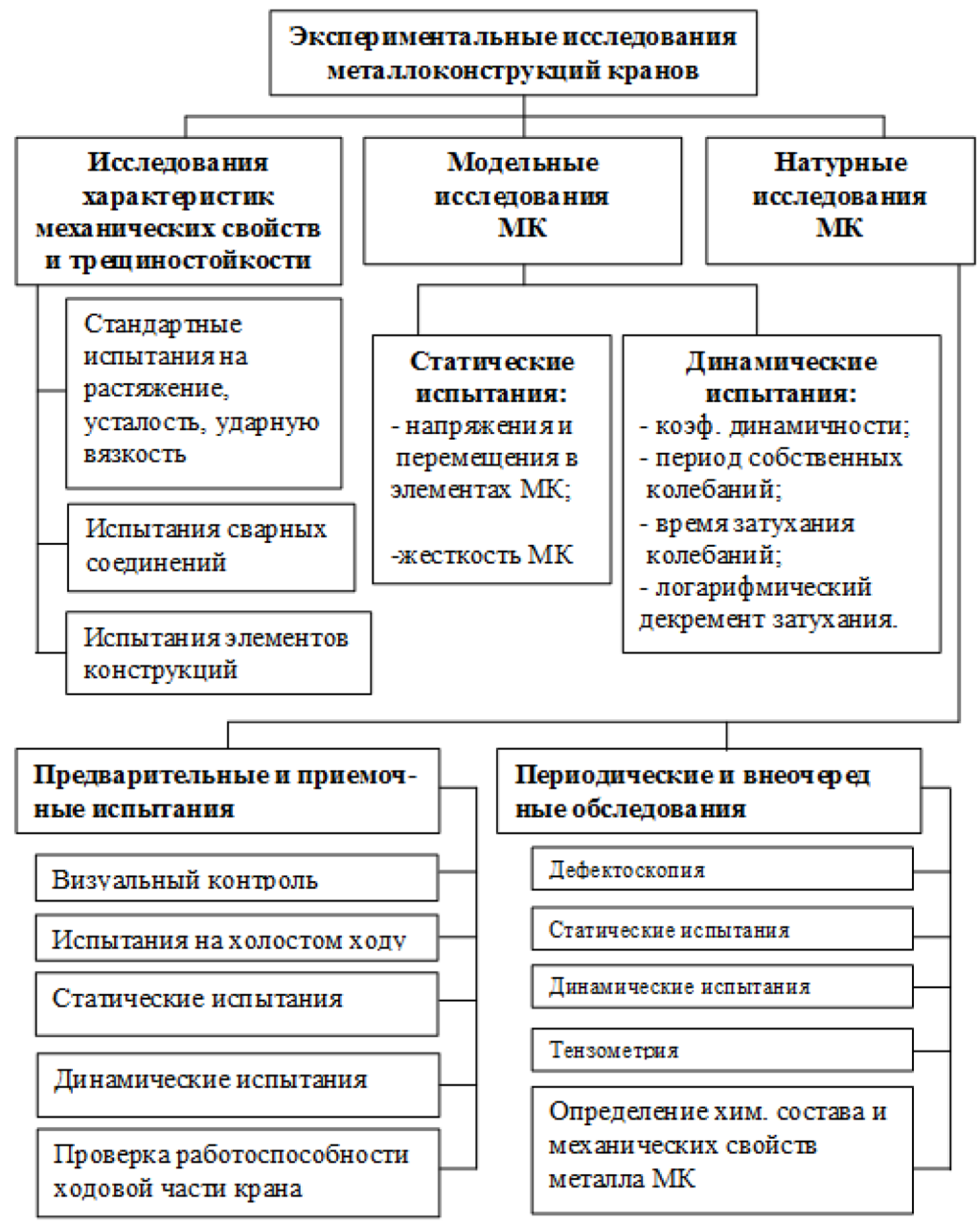

Рис. 2. Основные направления экспериментальных исследований металлоконструкций кранов

Fig. 2. Main directions of experimental research of crane metal structures

для образцов с технологическим дефектом (кривая 3) составляет $10 \ldots 30$ \% в диапазоне числа циклов нагружения $\mathrm{N}=2 \cdot 10^{4} \ldots 2 \cdot 10^{6}$, что послужило основной причиной возникновения и развития усталостных трещин.

В случае проведения модельных исследований МК форма и размеры моделей выбирают из условий их подобия натурным конструкциям в соответствии с существующими в конструкционном моделировании требованиями [39].

Были проведены модельные исследования блочных МК мостов для кранов общего назначения. В условиях циклического нагружения испытывали модели главных балок (рис. 5), прототипом которых являлась главная балка длиной пролета 17,0 м с толщиной верхнего пояса 16 мм крана общего назначения среднего режима работы грузоподъемностью 250/32 т. Была проведена серия испытаний шести балок-моделей, разбитых на три группы по две модели. В первой группе абразивным кругом снимали усиление сварных швов опорного узла с контролем по шаблону радиуса закругления. Во второй группе модели подвергались термообработке. Для 


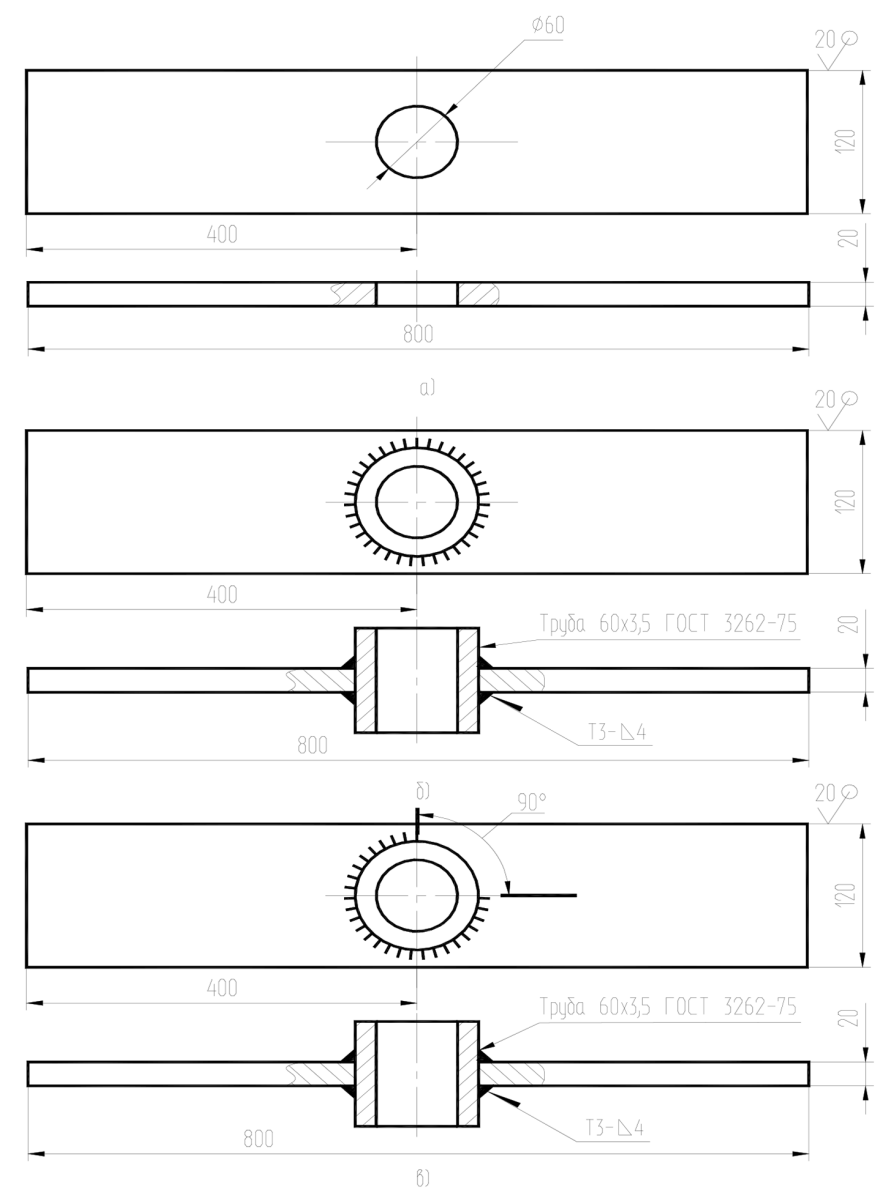

Рис. 3. Модельные образцы для испытания на усталость: а - с отверстием без окантовки; б - с окантовкой; в - с окантовкой при наличии технологического дефекта

Fig. 3. Model samples for fatigue testing: $a$ - with a hole without edging; $\sigma$ - with edging; $\mathrm{B}$ - with edging in the presence of a technological defect

снижения остаточных сварочных напряжений в моделях применялся отпуск при температуре $450{ }^{\circ} \mathrm{C}$ в течение 6 ч. В третьей - металл шва и околошовная зона в переходной области сечения балки подвергались поверхностному наклепу ударным бойком.

Испытания проводили на гидропульсационной установке типа ГРМ-2 с предельным усилием при циклическом нагружении до 500 кН. Модели устанавливали на специальном столе подвижной траверсы с опиранием на две цилиндрические вращающиеся опоры. Нагружение осуществляли пуансоном в середине пролета модели балки. Все испытания проведены при нагрузках $\mathrm{P}_{\max }=350$ кH, $\mathrm{P}_{\min }=175$ кН и частоте нагружения 435 цикл/мин.

При испытаниях усталостные трещины зарождались по линии сварного шва приварки гнутого листа к вертикалам опорного узла с последующим выходом в основной металл вертикальных листов (рис. 5). Проведенные испытания показали следующее. Обработка внешних сварных швов опорного узла абразивным кругом с целью снятия усиления и получения плавного перехода от шва к основному металлу не приводит к повышению усталостной прочности моделей опорного узла (по сравнению с базовыми моделями). Испытания моделей балок, не подвергавшихся 


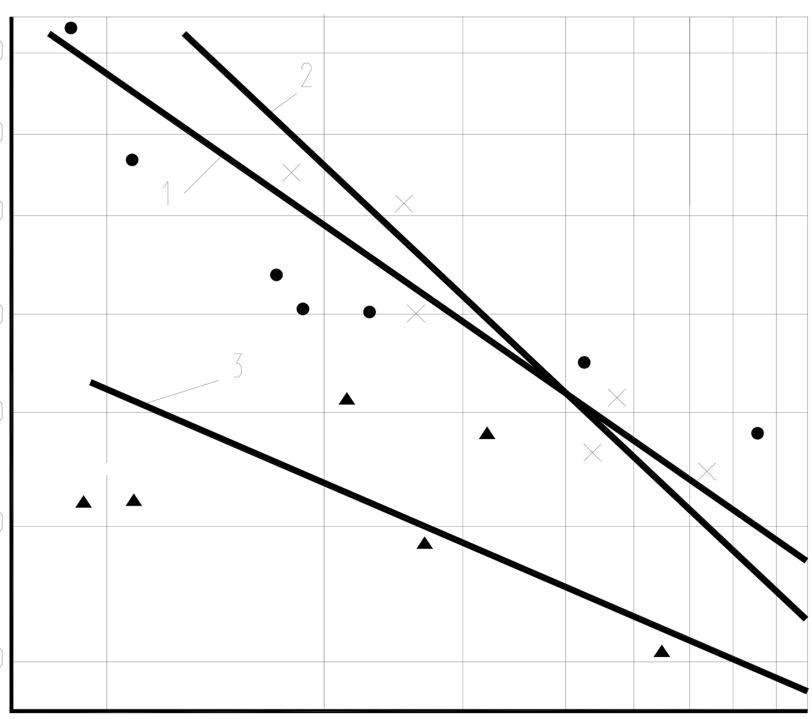

$1(\bullet)$ - первая; 2 (х) - вторая; 3 ( $\mathbf{\Delta})$ - третья партии

Рис. 4. Кривые усталости образцов по рис. 3. Сталь 09Г2С

Fig. 4. Fatigue curves of samples from Fig. 3. Steel 09Г2C

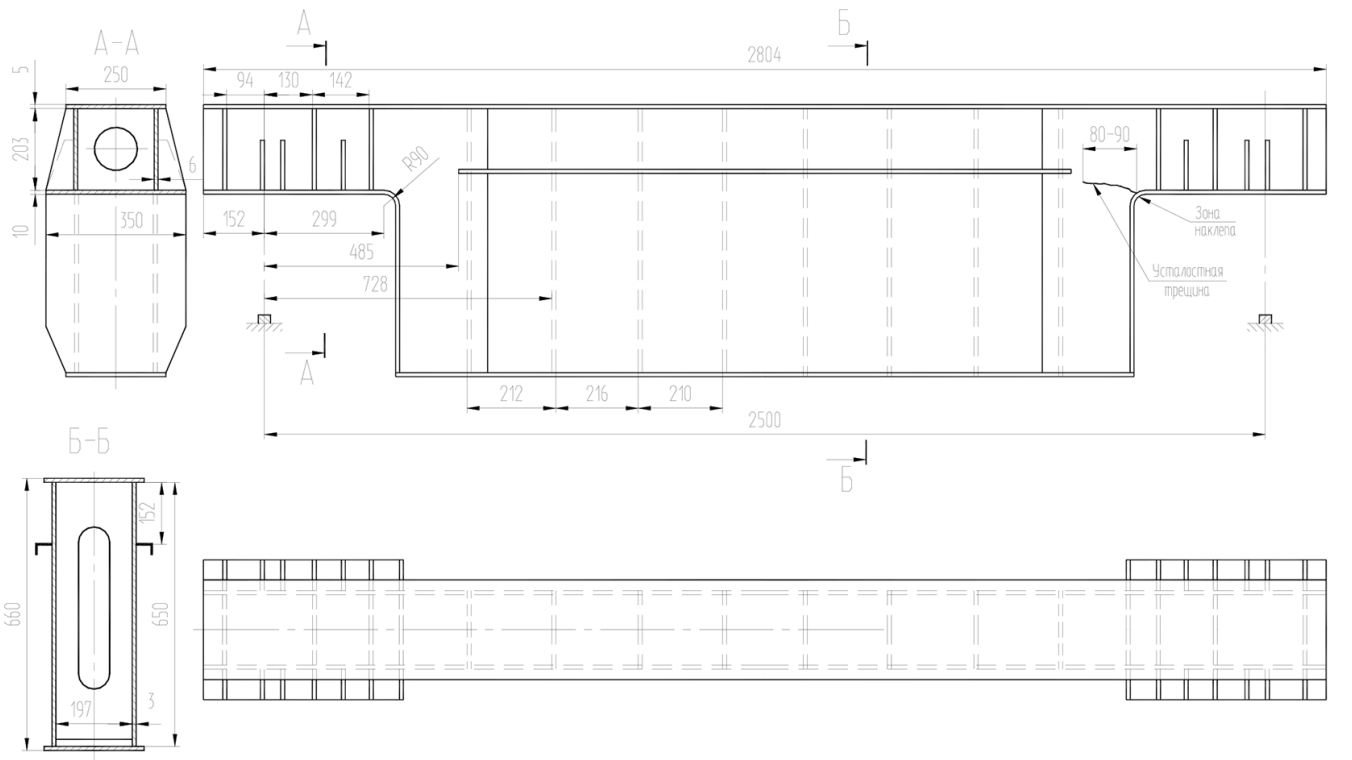

Рис. 5. Модель главной балки мостовых кранов блочной конструкции для испытаний на усталость

Fig. 5. Model of the main beam of bridge cranes of block construction for fatigue testing

термической обработке, продемонстрировали, что при одинаковых нагрузках они выдерживают большее число циклов нагружения, чем балки-модели после высокого отпуска. Наибольшее число циклов до разрушения выдержали балки-модели с обработкой сварного шва ударным бойком. 


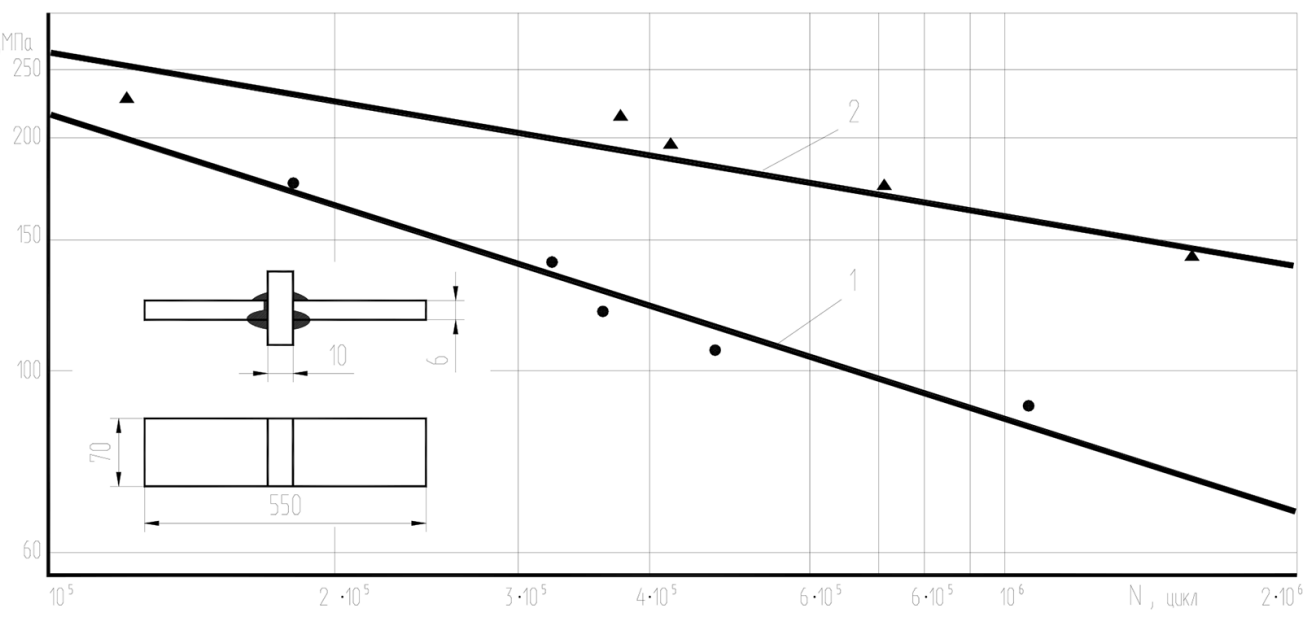

Рис. 6. Кривые усталости образцов с тавровым сварным швом: 1 - без обработки шва; 2 - с обработкой поверхностным наклепом

Fig. 6. Fatigue curves of samples with a tee-butt weld: 1 - without seam treatment; 2 - with surface cold working treatmen

В дополнение к испытаниям моделей для оценки усталостной прочности сварного соединения гнутых и вертикальных листов в переходной области поперечного сечения балки были проведены усталостные испытания двух серий образцов с тавровыми сварными соединениями на осевое растяжение. Испытывали образцы без обработки сварных швов и с обработкой поверхностным наклепом металла шва и околошовной зоны. Кривые усталости, представленные на рис. 6, однозначно указывают на целесообразность применения технологии поверхностного упрочнения. Предел выносливости образцов (коэффициент асимметрии $\mathrm{R}=-0,3$ ) после упрочнения повышается на базе $\mathrm{N}=2 \cdot 10^{6}$ циклов нагружения в два раза, что подтверждает результаты модельных испытаний. Проведенные исследования позволили рекомендовать технологию поверхностного упрочнения ударным воздействием бойка для внедрения в технологические процессы производства сварных крановых конструкций.

\section{5. Анализ напряженно-деформированных состояний крановых конструкций}

Важнейшая составная часть анализа предельных состояний - исследование НДС МК. В настоящее время основной технологией анализа НДС является конечноэлементное моделирование с помощью соответствующего программного обеспечения. В работе использовалось программное обеспечение ANSYS. Результаты расчетов представлялись в виде эпюр силовых факторов и напряжений, изолиний максимальных главных напряжений, эквивалентных напряжений (по условию Треска или Мизеса), линейных и угловых перемещений узлов. Были выполнены расчеты типовых элементов крановых МК [40-43]:

- пролетной балки мостового крана грузоподъемностью 200 т;

- рамы тележки мостового крана (грузоподъемность Q = 65 т) и мульдозавалочного крана $(\mathrm{Q}=5 / 20$ т);

$$
-945-
$$


- грузоподъемной траверсы мостового крана $(\mathrm{Q}=80$ т);

- главного балансира мостового крана $(\mathrm{Q}=125$ т);

- опорного узла концевой балки мостового крана;

- шахты главной тележки мульдозавалочного крана $(\mathrm{Q}=5 / 20$ т);

- $\quad$ кронштейна крепления мотор-редуктора механизма вращения крюка $(\mathrm{Q}=50$ т).

В ряде случаев были выполнены многовариантные расчеты различных конструктивных решений. В частности, анализировалось три варианта конструктивных решений серьги крановой подвески грузоподъемностью 15 т с детальным анализом НДС в зонах конструктивной концентрации напряжений. Для решения задач, требующих разработки сложных конечноэлементных моделей, использовали метод подконструкций (суперэлементов).

Накопленный опыт численного моделирования, исследования и оптимизации параметров НДС позволил заметно уменьшить металлоемкость ряда типовых МК и вместе с тем обеспечить повышение прочностных параметров кранов.

\section{6. Расчетные оценки на трещиностойкость, ресурс и надежность}

Расчеты МК на трещиностойкость выполняли для элементов с учетом мест расположения областей эксплуатационных повреждений, выявленных при освидетельствовании технического состояния крановых конструкций.

При проведении расчетов на трещиностойкость элементов крановых МК с реальными трещинами усталостного происхождения достаточным оказывается использование нескольких базовых расчетных схем в зависимости от конструктивного оформления элемента, условий их работы, зон расположения трещин. Для плоских элементов, являющихся основными для МК мостовых кранов, рекомендуется четыре базовых расчетных схемы. Для элементов, содержащих сварные соединения, устанавливаются три базовых расчетных схемы работы $[44,45]$.

При анализе показателей несущей способности выделяют основные и дополнительные типы предельных состояний. В обоих случаях в качестве показателей несущей способности используются коэффициенты запаса. Для основных типов предельных состояний система коэффициентов запаса включает традиционные коэффициенты запаса по пределам текучести и прочности, по предельным нагрузкам и деформациям, запас по пределу выносливости. Для дополнительных типов предельных состояний (хрупкое, квазихрупкое, вязкое разрушение, усталостное развитие трещин) вводятся коэффициенты запаса на основе критериев механики разрушения по нагрузкам, напряжениям и деформациям, по характеристикам трещиностойкости, числу циклов нагружения, размерам дефектов. Трактовка коэффициентов запаса как параметров, ограничивающих наступление предельных состояний, позволяет рассматривать их как количественные показатели несущей способности машин и конструкций.

Расчет на трещиностойкость при номинальных напряжениях $\sigma_{\mathrm{H}}<0,8 \sigma_{\mathrm{T}}$ может быть проведен в терминах критических напряжений или коэффициентов интенсивности напряжений

$$
\begin{aligned}
& \sigma_{\mathrm{H}}=\sigma_{1 \max } \leq\left[\sigma_{\mathrm{c}}\right]=\frac{\sigma_{\mathrm{C}}}{\mathrm{n}_{\sigma}} ; \\
& \mathrm{K}_{\mathrm{I}} \leq\left[\mathrm{K}_{\mathrm{c}}\right]=\frac{\mathrm{K}_{\mathrm{c}}}{\mathrm{n}_{\mathrm{K}}}
\end{aligned}
$$


где $\sigma_{\mathrm{c}}$ - разрушающее напряжение образца или элемента конструкции с трещиной; $\left[\sigma_{\mathrm{c}}\right],\left[\mathrm{K}_{\mathrm{c}}\right]-$ допускаемые значения разрушающих напряжений и критического коэффициента интенсивности напряжений; $\mathrm{K}_{\mathrm{c}}$ - критическое значение коэффициента интенсивности напряжений для образца или элемента конструкции; $\mathrm{n}_{\sigma}, \mathrm{n}_{\mathrm{k}}$ - коэффициенты запаса по разрушающему напряжению и критическому коэффициенту интенсивности напряжений.

Для элементов конструкций, при эксплуатации которых возможно возникновение номинальных напряжений как в упругой, так и в упруго-пластической области деформирования, расчет на трещиностойкость рекомендуется проводить с использованием уравнения $\mathrm{J}$ - проектной кривой

$$
\begin{aligned}
& \phi=\frac{\mathrm{J}_{\mathrm{c}} \mathrm{E}}{\pi \mathrm{l}_{\mathrm{c}} \sigma_{\mathrm{T}}^{2}}=\left(\mathrm{e}_{\mathrm{\kappa}} / \mathrm{e}_{\mathrm{T}}\right)^{2} \text { при } \mathrm{e}_{\mathrm{i}_{\mathrm{c}}} / \mathrm{e}_{\mathrm{T}} \leq 0,8 \\
& \phi=\frac{\mathrm{J}_{\mathrm{c}} \mathrm{E}}{\pi l_{\mathrm{c}} \sigma_{\mathrm{T}}^{2}}=1,12\left(\mathrm{e}_{\mathrm{\kappa}} / \mathrm{e}_{\mathrm{T}}\right) \quad \text { при } 0,8<\mathrm{e}_{\mathrm{i}_{\mathrm{c}}} / \mathrm{e}_{\mathrm{T}} \leq 5,0,
\end{aligned}
$$

где $\mathrm{J}_{\mathrm{c}}$ - критическое значение J-интеграла для элемента конструкции; $\mathrm{E}, \sigma_{\mathrm{T}}$ - модуль упругости и предел текучести; $\mathrm{e}_{\mathrm{ic}}-$ критическое значение эквивалентной деформации по сечению элемента без учета наличия трещины; $\mathrm{e}_{\mathrm{K}}$ - предельная деформация; $\mathrm{e}_{\mathrm{T}}-$ деформация, соответствующая пределу текучести (е $\left.\mathrm{e}_{\mathrm{T}}=\sigma_{\mathrm{T}} / \mathrm{E}\right)$.

В условиях циклического нагружения оценка предельного состояния элементов конструкций с трещиной осуществляется по уравнению Пэриса, интегрирование которого позволяет определить число циклов развития трещины от начального дефекта $1_{0}$ до критического $1_{c}$.

Таким образом, при расчетах несущей способности крановых металлоконструкций должны рассматриваться две группы коэффициентов запаса для основных и дополнительных типов предельных состояний, номенклатура и значение которых приведены в табл. 2.

Одним из наиболее нагруженных узлов мостового крана считается концевая балка. Анализ данных периодического технического диагностирования показывает, что усталостные тре-

Таблица 2. Значения коэффициентов запаса при расчетах крановых металлоконструкций

Table 2. Values of safety factors in the calculation of the crane metal structures

\begin{tabular}{|l|c|c|}
\hline \multicolumn{1}{|c|}{ Назначение коэффициента запаса } & Обозначение & $\begin{array}{c}\text { Значение } \\
\text { коэффициента }\end{array}$ \\
\hline І.Основные типы предельных состояний & & $1,2 \ldots 2,0$ \\
\hline Коэффициент запаса по пределу текучести & $\mathrm{n}_{\mathrm{r}}$ & $1,5 \ldots .2,5$ \\
\hline Коэффициент запаса по пределу прочности & $\mathrm{n}_{\mathrm{B}}$ & $1,5 \ldots 3,0$ \\
\hline Коэффициент запаса по амплитудам переменных напряжений & $\mathrm{n \sigma}_{\mathrm{a}}$ & $1,2 \ldots 1,6$ \\
\hline Запас по предельным нагрузкам & $\mathrm{n}_{\mathrm{F}}$ & $1,75 \ldots 2,5$ \\
\hline ІІ. Дополнительные типы предельных состояний & & $1,7 \ldots .2,5$ \\
\hline Коэффициент запаса по разрушающим напряжениям & $\mathrm{N \sigma}_{\mathrm{c}}$ & $3 \ldots 10$ \\
\hline Коэффициенты запаса по характеристикам трещиностойкости & $\mathrm{n}_{\mathrm{K}}, \mathrm{n}_{\mathrm{J}}$ & \\
\hline Коэффициент запаса по числу циклов до разрушения & $\mathrm{n}_{\mathrm{N}}$ & 2,0 \\
\hline Коэффициент запаса по размеру трещин & $\mathrm{n}_{l}$ & \\
\hline
\end{tabular}




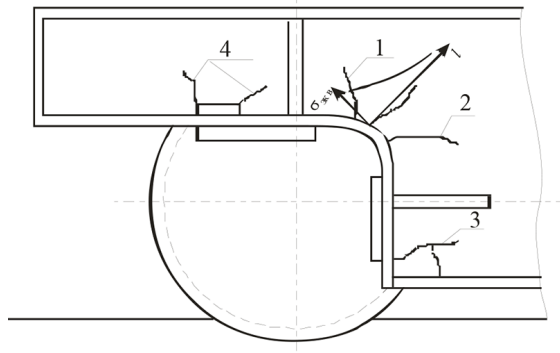

a)

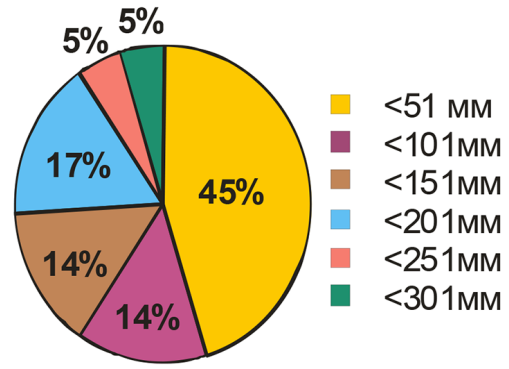

б)

Рис. 7. Зона крепления буксы ходового колеса в концевой балке мостового крана (1-4 - траектории усталостных трещин) (а). Статистические данные по размерам трещин в опорных узлах мостовых кранов (б)

Fig. 7. Mounting area of the undercarriage wheel axle box in the end beam of the bridge crane (1-4 - trajectories of fatigue cracks) (a). Statistical data on the cracks size in the support nodes of bridge cranes (б)

щины в опорном узле являются наиболее характерным видом повреждения при сроках эксплуатации кранов свыше $6 \ldots 8$ лет (рис. 7). Характер нагружения данного узла определяется как двухчастотный с основной составляющей от веса перемещаемого груза и дополнительной от воздействия рабочих механизмов. С учетом этого был проведен расчет ресурса типовых конструктивных вариантов для кранов малой и средней грузоподъемности (до 60 т).

Оценку ресурса поврежденного элемента рассмотрим на примере опорного узла концевой балки мостового крана [44-46]. Данный узел наиболее высоконагруженный в силу следующих причин: 1) в этой зоне наблюдается резкое изменение высоты сечения балки в сторону уменьшения для размещения ходового колеса в условиях жестких ограничений на общую высоту моста; 2) в этом узле сходятся все силовые потоки, формируемые условиями нагружения, которые передаются через ходовое колесо на подкрановый путь; 3) опорный узел непосредственно воспринимает динамические реактивные воздействия, возникающие при прохождении колесом стыка рельса и при ударе реборды колеса о боковую поверхность головки рельса. Усталостные повреждения данного узла являются типичным предельным состоянием для кранов любой грузоподъемности и режима работы [46].

Оценка параметров напряженного состояния (рис. 8а) выполнена с помощью конечно-элементной модели, использующей плоские восьмиузловые изопараметрические конечные элементы, воспринимающие все виды деформирования (растяжение, изгиб, кручение) в упругой области и обладающие 48 степенями свободы. Модель содержит все основные несущие элементы конструкции: вертикальные листы переменной высоты, гнутый лист в переходном сечении, верхний и нижний пояса, платики крепления ходовой буксы, вертикальное и горизонтальное ребра жесткости. Вместе с опорным узлом смоделирована часть концевой балки, длина которой определена с учетом принципа Сен-Венана из тех соображений, чтобы напряженное состояние в зоне закрепления модели не оказывало влияние на распределение напряжений и деформаций непосредственно в опорном узле.

Расчет включал численный анализ напряженно-деформированного состояния узла без трещин и при наличии усталостных трещин длиной $30 \ldots 500$ мм (рис. 8); определение коэф- 


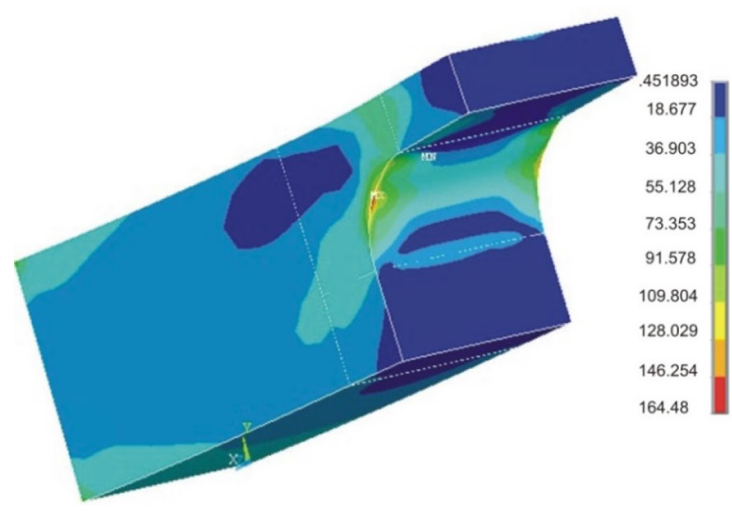

a)

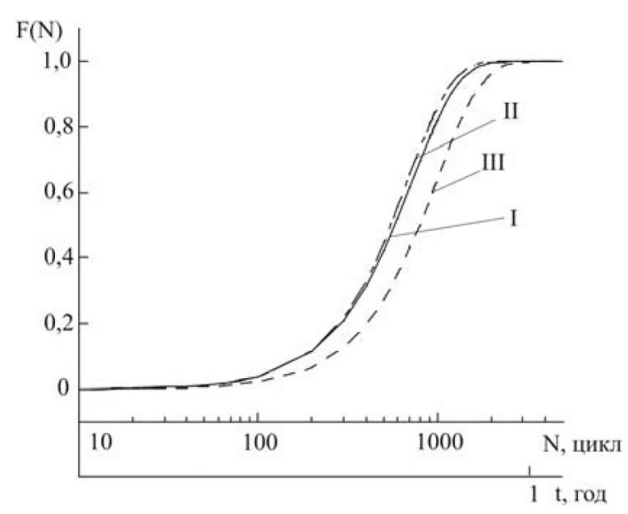

б)

Рис. 8. Распределение эквивалентных напряжений опорного узла концевой балки (МПа) (а). Функции распределения ресурса в зависимости от числа циклов наработки (б)

Fig. 8. Distribution of equivalent stresses of the support unit of end beam (MPa) (a). Resource distribution functions depending on the number of operating cycles (б)

фициента интенсивности напряжений и вероятностный расчет ресурса узла на стадии роста усталостных трещин. В результате расчета НДС установлена наиболее нагруженная зона конструкции, которая фактически совпадает с областью возникновения усталостных трещин. Коэффициент интенсивности напряжений вычислялся согласно [47]:

$$
K_{I}=\frac{6 M}{t W^{2}} \sqrt{\pi l} F_{I}(\alpha)
$$

где $M$ - рабочий изгибающий момент; $W$ - ширина пластины; $t$ - толщина пластины; $F_{I}(\alpha)-$ поправочная функция. В расчетах принимали значения $M=28284$ Н·м (по данным конечноэлементного расчета); $W=0,5 \mathrm{м} ; t=0,012$ м.

$$
F_{I}(\alpha)=1,122-1,40 \alpha+7,33 \alpha^{2}-13,08 \alpha^{3}+14,0 \alpha^{4},
$$

где $\alpha=t / W$ при $\alpha \leq 0,6$.

Задачу решали для трех расчетных случаев с количественными параметрами, представленными в табл. 3. Материал - сталь 09Г2С, $\left(\sigma_{\mathrm{T}}=370 \mathrm{MПа;} \sigma_{\mathrm{B}}=525 \mathrm{MПа}\right)$. Начальные размеры трещин определялись из условия реальной выявляемости дефектов при визуальном контроле 5...10 мм. Расчеты ресурса выполнены на основе кинетического уравнения, учитывающего двухчастотный характер нагружения [46].

Исходные данные для каждой задачи принимали с учетом начальных параметров распределений, описывающих те или иные характеристики с использованием алгоритмического генератора случайных чисел. Расчет по кинетической модели проводили многократно в зависимости от числа заданных итераций. В результате статистической обработки получены функции распределения ресурса и надежности, представленные в табл. 3. На рис. 8 приведены функции распределения ресурса для расчетных случаев в зависимости от числа циклов эксплуатации и времени наработки. Как следует из расчетов, высокая безотказность обеспечивается: в первом случае при $1,4 \cdot 10^{3}$ циклов нагружения узла; во втором - при $1,2 \cdot 10^{3}$ циклов, в третьем - при $1,8 \cdot 10^{3}$ циклов.

$$
-949-
$$


Таблица 3. Исходные данные и результаты расчета ресурса элемента крана

Table 3. Source data and results of calculating the crane element resource

\begin{tabular}{|c|c|c|c|}
\hline & \multicolumn{3}{|c|}{ Расчетный случай } \\
\hline & I & II & III \\
\hline$\sigma_{\max \_ \text {экв }} / \sigma_{\mathrm{T}}$ & 0,45 & 0,45 & 0,38 \\
\hline$\sigma_{\mathrm{m}} / \sigma_{\mathrm{T}}$ & 0,23 & 0,25 & 0,2 \\
\hline$\sigma_{1} / \sigma_{\mathrm{T}}$ & 0,16 & 0,14 & 0,12 \\
\hline$\sigma_{2} / \sigma_{\mathrm{T}}$ & 0,06 & 0,06 & 0,06 \\
\hline$\omega_{2} / \omega_{1}$ & 20 & 30 & 30 \\
\hline $\mathrm{m}_{l_{0}}, \mathrm{MM}$ & 5 & 10 & 10 \\
\hline $\mathrm{s}_{l_{0}}, \mathrm{MM}$ & 3 & 5 & 5 \\
\hline $\begin{array}{l}\text { Функции распределения } \\
\text { ресурса }\end{array}$ & $F(N)=1-e^{-\left(\frac{N}{719.72}\right)^{1.66}}$ & $F(N)=1-e^{-\left(\frac{N}{675.62}\right)^{1.73}}$ & $F(N)=1-e^{-\left(\frac{N}{983.74}\right)^{1.69}}$ \\
\hline Функции надежности & $R(N)=e^{-\left(\frac{N}{719.72}\right)^{1.66}}$ & $R(N)=e^{-\left(\frac{N}{675.62}\right)^{1.73}}$ & $R(N)=e^{-\left(\frac{N}{983.74}\right)^{1.69}}$ \\
\hline
\end{tabular}

Примечание. $\mathrm{m}_{l_{0}}, \mathrm{~s}_{l_{0}}$ - математическое ожидание и среднее квадратическое отклонение начальной трещины; $\sigma_{\mathrm{m}}-$ среднее напряжение цикла; $\sigma_{1}, \sigma_{2}$ - напряжения в цикле соответствующей частоты $\omega_{1}$ и $\omega_{2} ; \sigma_{\max }$ - максимальное напряжение бигармонического нагружения.

\section{Заключение}

Экспериментальные и теоретические исследования крановых МК в конечном итоге находят применение в нормативных документах, регламентирующих методы определения прочности и ресурса МК. Расчеты на усталость на базе этих методов предполагают оценки долговечности на стадии возникновения трещины или на стадии окончательного разрушения. Такой подход не позволяет давать оценки уровней накопленных повреждений и остаточного ресурса конструкций на различных стадиях эксплуатации крановых МК. Важность решения этой задачи становится все более актуальной в связи с проблемой остаточного ресурса и стимулирует применение методов механики разрушения и теории надежности механических систем к расчетам металлоконструкций ПТМ на стадии развития усталостных трещин. Выполненные в этом направлении работы $[21,22$, $44,45,48]$ показали перспективность дополнения традиционных методов подходами, развиваемыми в рамках механики разрушения, к расчетам остаточного ресурса на стадии эксплуатации и его прогнозирования на стадии проектирования для возможных аварийных ситуаций $[44,49,50]$.

Дальнейшее развитие методологических подходов к проектированию крановых конструкций связано с применением подходов теории безопасности технических систем. Первоочередными задачами при этом являются: 1) уточнение перечня расчетных случаев проектирования, т.е. наиболее неблагоприятных комбинаций нагрузок, условий опирания и внешних факторов; 2) моделирование гипотетических аварийных ситуаций и исследование поведения крановых конструкций в нештатных условиях; 3) численное моделирование живучести несущих конструкций при развитии повреждений в номинальных и аварийных условиях эксплуатации; 4) формулировка требований и алгоритмов построения конструктивных форм высокой живучести, устойчивых к начальной дефектности и эксплуатационным повреждениям.

$$
-950-
$$




\section{Список литературы / References}

[1] Богинский К.С., Зотов Ф.С., Николаевский Г.М. Мостовые и металлургические краны. М.: Машиностроение, 1969. 300 с. [Boginskiy K.S., Zotov F.S., Nikolaevskiy G.M. Bridge and metallurgical cranes. Moscow: Mashinostroenie, 1969. 300 p. (in Russian)]

[2] Справочник по кранам. В 2 т. Под общ. ред. М.М. Гохберга. М.: Машиностроение, 1988. T. 1. 536 c.; T. 2. 559 c. [Handbook on cranes: in two volumes. Under the general editorship of Gokhberg M.M. Moscow: Mashinostroenie, 1988. Vol. 1. 536 p.; Vol. 2. 559 p. (in Russian)]

[3] Вайнсон А.А. Подъемно-транспортные машины. М.: Машиностроение, 1975. 431 с. [Vaynson A.A. Handling machinery. Moscow: Mashinostroenie, 1975. 431 p. (in Russian)]

[4] Грузоподъемные машины. М.П. Александров, Л.Н. Колобов, И.П. Крутиков и др. М.: Высшая школа, 1973. 473 с. [Hoisting machinery. Aleksandrov M.P., Kolobov L.N., Krutikov I.P. et al. Moscow: Vyshaya schkola, 1973. 473 p. (in Russian)]

[5] Иванченко Ф.К. Конструкции и расчет подъемно-транспортных машин. Киев: Вища школа, 1983. 351 с. [Ivanchenko F.K. Construction and calculation of handling machinery. Kyiv: Visha schkola, 1983. 351 p. (in Russian)]

[6] Павлов Н.Г. Примеры расчетов кранов. Л.: Машиностроение, 1976. 320 с. [Pavlov N.G. Examples of calculations of the cranes. Leningrad: Mashinostroenie, 1976. 320 p. (in Russian)]

[7] Казак С.А. Динамика мостовых кранов. М.: Машиностроение, 1968. 332 с. [Kazak S.A. Dynamics of bridge cranes. Moscow: Mashinostroenie, 1968. 332 p. (in Russian)]

[8] Лобов Н.А. Динамика грузоподъемных кранов. М.: Машиностроение, 1987. 160 с. [Lobov N.A. Dynamics of hoisting cranes. Moscow: Mashinostroenie, 1987. 160 p. (in Russian)]

[9] Брауде В.И., Семенов Л.Н. Надежность подъемно-транспортных машин. Л.: Машиностроение, 1986. 183 c. [Braude V.I., Semenov L.N. Reliability of handling machines. Leningrad: Mashinostroenie, 1986. 183 p. (in Russian)]

[10] Шишков Н.А. Надежность и безопасность грузоподъемных машин. М.: Недра, 1990. 252 c. [Shishkov N.A. The reliability and safety of hoisting machines. Moscow: Nedra, 1990. 252 p. (in Russian)]

[11] Вершинский А.В. Технологичность и несущая способность крановых металлоконструкций. М.: Машиностроение, 1984. 167 с. [Vershinskiy A.V. Produceability and load-bearing capacity of crane metal structures. Moscow: Mashinostroenie, 1984. 167 p. (in Russian)]

[12] Рыжков Н.И. Производство сварных конструкций в тяжелом машиностроении. М.: Машиностроение, 1980. 375 c. [Ryzhkov N.I. Manufacturing of welded structures in heavy engineering. Moscow: Mashinostroenie, 1980. 375 p. (in Russian)]

[13] Винокурский Х.А. Расчет пространственных крановых мостов. Свердловск: Машгиз, 1948. 123 с. [Vinokurskiy Kh.A. Computation of three-dimensional crane bridges. Sverdlovsk: Mashgiz, 1948. 123 p. (in Russian)]

[14] Богуславский П.Е. Строительная механика крановых металлоконструкций. М.: Машгиз, 1944. 187 с. [Boguslavskiy P.E. Construction mechanics of crane metal structures. Moscow: Mashgiz, 1944. 187 p. (in Russian)]

[15] Мельников Н.П. Развитие конструктивной формы крановых металлоконструкций. Исследование и развитие теории конструктивных форм крановых металлоконструкций. М.: ЦНИИпроектстальконструкция, 1982. С. 3-40 [Mel'nikov N.P. Development of the structural 
form of crane metal structures. Research and development of the theory of structural forms of crane metal structures. Moscow: Central Research and Design Institute of Steel Structures, 1982. P. 3 - 40 (in Russian)]

[16] РТМ 24.190.07-85. Нормы расчета стальных конструкций мостовых кранов грузоподъемностью свыше 50 т. Минтяжмаш. М.: МВТУ, 1985. 102 с. [Technical Guides 24.190.07-85. Calculation standards for steel structures of bridge cranes with a load capacity of more than 50 tons. The Ministry of Heavy Machine Building. Moscow: Moscow Higher Technical School, 1985. 102 p. (in Russian)]

[17] РД 24.090.83-87. Нормы расчета пространственных металлоконструкций грузоподъемных кранов атомных станций на эксплуатационные и сейсмические воздействия. М.: Минтяжмаш, 1987. 72 с. [RD 24.190.07-85. Norms for calculating spatial metal structures of nuclear power plant lifting cranes for operational and seismic impacts. Moscow: The Ministry of Heavy Machine Building, 1987. 72 p. (in Russian)]

[18] РД 24.035.04-89. Нормы расчета на сейсмостойкость подъемно-транспортного оборудования атомных станций. М.: Минтяжмаш, 1989. 64 с. [RD 24.035.04-89. Calculation standards for seismic stability of lifting and transport equipment of nuclear power plants. Moscow: The Ministry of Heavy Machine Building, 1989. 64 p. (in Russian)]

[19] Мельников Н.П. Развитие конструктивной формы крановых металлоконструкций. Исследование и развитие теории конструктивных форм крановых металлоконструкций. М.: ЦНИИпроектстальконструкция, 1982. С. 3-40 [Mel'nikov N.P. Development of the structural form of crane metal structures. Research and development of the theory of structural forms of crane metal structures. Moscow: Central Research and Design Institute of Steel Structures, 1982. P. 3 - 40 (in Russian)]

[20] Гостяев В.И., Москвичева Л.Ф. Эксплуатационная надежность и предельные состояния металлоконструкций мостовых кранов. Современные методы математического моделирования природных и антропогенных катастроф. Красноярск: ИВМ СО РАН, 1999. С. $115-$ 117. [Gostyaev V.I., Moskvicheva L.F. Operational reliability and limit states of metal structures of bridge cranes. Modern methods of mathematical modeling of natural and anthropogenic disasters. Krasnoyarsk: Institute of Computational Modeling of the SB RAS, 1999. P. 115-117 (in Russian)]

[21] Воронцов Г.А., Дувидович Д.И. К вопросу о хрупком разрушении металлоконструкций кранов в различных условиях эксплуатации. Исследование крановых металлоконструкций. Тр. ВНИИПТМАШ, 1979. Вып. 1. С. 87-109. [Vorontsov G.A., Duvidovich D.I. To the question of brittle destruction of crane metal structures in various operating conditions. Research of crane metal structures. VNIIPTMASH proceedings, 1979. No. 1, 87-109 (in Russian)]

[22] Пустовой В.Н. Металлоконструкции грузоподъемных машин. Разрушение и прогнозирование остаточного ресурса. М.: Транспорт, 1992. 256 с. [Pustovoy V.N. Metal structures of lifting machines. Destruction and prediction of the remaining lifetime. Moscow: Transport, 1992. 256 p. (in Russian)]

[23] Москвичева Л.Ф., Козлов А.Г. Трещиностойкость сталей крановых металлоконструкций. Природно-техногенная безопасность Сибири. Тр. научных мероприятий. Красноярск: КГТУ, 2001. Т. 2. С. 268-273. [Moskvicheva L.F., Kozlov A.G. The fracture toughness of the steel of crane metal structures. Natural and technogenic safety of Siberia. Proceedings of scientific events. Krasnoyarsk: Krasnoyarsk state technical University, 2001. Vol. 2. 268-273 (in Russian)]

$$
-952-
$$


[24] Трещиностойкость и механические свойства конструкционных материалов технических систем. В.В. Москвичев, Н.А. Махутов, А.П. Черняев, Л.Ф. Москвичева и др. Новосибирск: Наука, 2002. 334 c. [Crack resistance and mechanical properties of structural materials of technical systems. Moskvichev V.V., Makhutov N.A., Chernyaev A.P., Moskvicheva L.F. Novosibirsk: Nauka, 2002. 334 p. (in Russian)]

[25] Концевой Е.М., Розеншейн Б.М. Ремонт крановых металлоконструкций. М.: Машиностроение, 1979. 206 с. [Kontsevoy E.M., Rozeshein B.M. Repair of crane metal structures. Moscow: Mashinostroenie, 1979. 206 p. (in Russian)]

[26] Исследование динамических нагрузок в многомассовой схеме механизма главного подъема литейного крана. К.Д. Никитин, С.А. Казак, Е.С. Кузнецов, А.А. Колотыгин. Грузоподъемные краны. Тр. вузов Российской Федерации. Свердловск: УПИ, 1976. С. 22-28. [Study of dynamic loads in a multi-mass scheme of the main lifting mechanism of a foundry crane. Nikitin K.D., Kazak S.A., Kuznetsov E.S., Kolotygin A.A. Hoisting cranes. Proceedings of higher education institutions of the Russian Federation. Sverdlovsk: Ural Polytechnic Institute, 1976. P. 22-28 (in Russian)]

[27] Балашов В.П. Боковые силы в кранах мостового типа в периоды пуска и торможения. Исследование динамики грузоподъемных кранов. Тр. ВНИИПТМАШ. М., 1970. Вып. 5(100). C. 45-59. [Balashov V.P. Lateral forces in bridge type of cranes during start-up and braking periods. Study of the lifting cranes dynamics. VNIIPTMASH proceedings. Moscow, 1970. No. 5(100). P. 45-59 (in Russian)]

[28] Гохберг М.М., Богинский К.С. Исследование напряженного состояния опорных узлов коробчатых балок ступенчатой формы металлических конструкций кранов. Металлические конструкции кранов. Исследование конвейеров. Тр. ЛПИ. Л.: ЛПИ, 1975, 347, 7-10. [Gokhberg M.M., Boginskiy K.S. Investigation of the stress state of support units of stepped form box beams of crane metal structures. Metal structures of cranes. Pipeline research / Proceedings of the Leningrad Polytechnic Institute. Leningrad: Leningrad Polytechnic Institute, 1975, 347, 7-10 (in Russian)]

[29] К вопросу о напряженном состоянии концевых балок мостовых кранов. Сумцов А.А., Станиславская В.Э., Манилов К.М., Фридган А.Л. Исследование крановых механизмов и металлоконструкций. М.: ВНИИПТМАШ, 1983. С. 14-25. [On the stress state of the end beams of bridge cranes. Sumtsov A.A., Stanislavskaya V.E., Manilov K.M., Fridgan A.L. Research of crane mechanisms and metal structures. Moscow: VNIIPTMASH, 1983. P. 14-25 (in Russian)]

[30] Дусье В.Е., Наварский Ю.В. О возможности повышения несущей способности мостов кранов. Грузоподъемные краны. Тр. вузов Российской Федерации. Свердловск: УПИ, 1976. С. 40-43. [Dusye V.E., Navarskiy Yu.V. On the possibility of increasing the bearing capacity of crane bridges. Hoisting cranes. Proceedings of higher education institutions of the Russian Federation. Sverdlovsk: Ural Polytechnic Institute, 1976. P. 40-43 (in Russian)]

[31] Хлавич П.С., Швалов Н.А., Якунцов И.Г. Экспериментальное исследование напряжений в поясах главных балок колодцевого крана. Пути технического развития крановых металлоконструкций. Сб. докл. науч.-техн. совещ. по крановым металлоконструкциям. М., 1966. С. 90-106. [Khlavich P.S., Shvalov N.A., Yakuntsov I.G. Experimental study of stresses in the belts of the main beams of a pit crane. Ways of technical development of crane metal structures. Book of reports of the scientific and technical meeting on crane metal structures. Moscow, 1966. P. 90-106 (in Russian)]

$$
-953-
$$


[32] Горохов Е.В., Карпенко Н.Т. Повышение долговечности металлических конструкций мостовых кранов. Киев: Вища школа, 1986. 147 с. [Gorokhov E.V., Karpenko N.T. Increasing the durability of metal structures of bridge cranes. Kyiv: Visha schkola, 1986. 147 p. (in Russian)]

[33] Павлов М.Е., Розенштейн Б.М. К вопросу о расчетной оценке прочности и жесткости пролетных балок серийных мостовых кранов. Исследование крановых механизмов и металлоконструкций. М.: ВНИИПТМАШ, 1983. С. 87-96. [Pavlov M.E., Rozenshtein B.M. On the calculating the strength and stiffness of span beams of serial bridge cranes. Research of crane mechanisms and metal structures. Moscow: VNIIPTMASH, 1983. P. 87-96 (in Russian)]

[34] Серенсен С.В., Когаев В.П., Шнейдерович Р.М. Несущая способность и расчеты деталей машин на прочность. М.: Машгиз, 1963. 451 с. [Serensen S.V., Kogaev V.P., Shneiderovich R.M. Load-bearing capacity and strength calculations of machine parts. Moscow: Mashgiz, 1963. $451 \mathrm{p}$. (in Russian)]

[35] Хейвуд Р.Б. Проектирование с учетом усталости. М.: Машиностроение, 1969. 503 с. [Kheivud R.B. Engineering with regard to fatigue. Moscow: Mashinostroenie, 1969. 503 p. (in Russian)]

[36] Юшкевич В.Н. Расчетное определение пределов выносливости элементов крановых металлоконструкций. Машиностроение. Тр. ЛПИ. Л.: Машиностроение, 1970, 314, 173-180. [Yushkevich V.N. Calculated determination of endurance limits for elements of crane metal structures. Mashinostroenie. Proceedings of the Leningrad Polytechnic Institute. Leningrad: Mashinostroenie, 1970, 314, 173-180 (in Russian)]

[37] Соколов С.А. Строительная механика и металлические конструкции машин. СПб.: Политехника, 2011. 450 c. [Sokolov S.A. Structural mechanics and metal structures of machines. St. Petersburg: Polytechnika (Magazine of Civil Engineering), 2011. 450 p. (in Russian)]

[38] Казак С.А. Статистическая динамика и надежность подъемно-транспортных машин. Свердловск: УПИ, 1987. 86 с. [Kazak S.A. Statistical dynamics and reliability of lifting and transport vehicles. Sverdlovsk: Ural Polytechnic Institute, 1987. 86 p. (in Russian)]

[39] Пригоровский Н.И. Методы и средства определения полей деформаций и повреждений. Справочник. М.: Машиностроение, 1983. 248 с. [Prigorovskiy N.I. Methods and tools for determining the fields of deformations and damages: Reference book. Moscow: Mashinostroenie, 1983. 248 p. (in Russian)]

[40] Москвичева Л.Ф. Исследования несущей способности металлоконструкций мостовых кранов повышенной грузоподъемности. Вычислительные технологии. 2001, 6. Спец. вып. Ч. 2, 310-317. [Moskvicheva L.F. Study of load-bearing capacity of metal structures of bridge cranes with increased load capacity. Computing technology, 2001, 6. Special issue, part 2, 310-317 (in Russian)]

[41] Доронин С.В., Москвичева Л.Ф., Гостяев В.И. Особенности анализа напряженно-деформированного состояния металлоконструкций мостовых кранов. Вестник КГТУ. Машиностроение. 2001, 22, 116-127. [Doronin S.V., Moskvicheva L.F., Gostyaev V.I. Analysis features of the stress-strain state of metal structures of bridge cranes. Reporter of the Krasnoyarsk state technical University. Mechanical engineering. 2001, 22, 116-127 (in Russian)]

[42] Доронин С.В., Москвичева Л.Ф. Технология решения многоуровневых задач при проектировании крановых металлоконструкций. Вычислительные технологии. Региональный вестник Востока. 2003. Совместный выпуск. Часть 1, 323-328. [Doronin S.V., Moskvicheva L.F. 
Technology for solving multi-level problems in the design of crane metal structures. Computing technology. Regional Bulletin of the East. 2003. Joint issue. Part 2, 323-328 (in Russian)]

[43] Москвичева Л.Ф., Скотников И.В. Оптимизационные расчеты металлоконструкций мостовых кранов. Вычислительные технологии. Вестник КазНУ им. Аль-Фараби, 2004. Совместный выпуск. Часть 3, 195-197. [Moskvicheva L.F., Skotnikov I.V. Optimization calculations of bridge crane metal structures. Computing technology. Bulletin of Al-Farabi Kazakh national University, 2004. Joint issue. Part 2, 195-197 (in Russian)]

[44] MP 38. 03. 001-02. Методы расчетной оценки остаточного ресурса металлоконструкций грузоподъемных кранов. Методические рекомендации. А.П. Черняев, А.М. Лепихин, Л.Ф. Москвичева, Н.А. Чернякова и др. Красноярск: НПП «СибЭРА», 2002. 40 с. [MR 38. 03. 001-02. Methods for calculating the residual life of metal structures of lifting cranes. Methodical recommendations. Chernyaev A.P., Lepikhin A.M., Moskvicheva L.F., Chernyakova N.A., et al. Krasnoyarsk: R\&D enterprise «Sibera», 2002. 40 p. (in Russian)]

[45] Прикладные задачи конструкционной прочности и механики разрушения. В.В. Москвичев, Н.А. Махутов, Ю.И. Шокин, А.М. Лепихин и др. Новосибирск: Наука, 2020. 830 с. [Applied problems of structural strength and fracture mechanics. Moskvichev V.V., Makhutov N.A., Shokin Yu.I., Lepikhin A.M., et al. Novosibirsk: Nauka, 2020. 830 p. (in Russian)]

[46] Чернякова Н.А. Оценка безопасности остаточного ресурса мостового крана на основе моделирования роста усталостных трещин. Вычислительные технологии, 2004, 9(4), 249-251. [Chernyakova N.A. Safety assessment of the residual life of a bridge crane based on modeling of fatigue crack growth. Computing technology, 2004, 9(4), 249-251 (in Russian)]

[47] Справочник по коэффициентам интенсивности напряжений. В 2 т. Т. 1. Пер. с англ. под ред. Ю. Мураками. М.: Мир, 1990. 448 с. [Handbook of stress intensity coefficients. In 2 volumes. Vol.1, translated from English, edited by Yu. Murakami. Moscow: Mir, 1990. 448 p. (in Russian)]

[48] Кинетика усталостного разрушения конструкционных сталей для подъемно-транспортного машиностроения. Г.А. Воронцов, П.А. Рахманов, Л.С. Михалочкина, С.Н. Рощин. Исследование крановых металлоконструкций. Тр. ВНИИПТМАШ. М.: ВНИИПТМАШ, 1979, 1, 76-86. [Fatigue failure kinetics of structural steels for lifting and transport engineering. Vorontsov G.A., Rakhmanov P.A., Mikhalochkina L.S., Roschin S.N. Research of crane metal structures. VNIIPTMASH proceedings. Moscow: VNIIPTMASH, 1979, 1, 76-86 (in Russian)]

[49] Методические указания по проведению обследования кранов с целью определения возможности их дальнейшей эксплуатации. Руководящий документ. М.: ВНИИПТМАШ, 1991. 53 c. [Guidelines for conducting a survey of cranes in order to determine the possibility of their further operation. Guidance document. Moscow: VNIIPTMASH, 1991. 53 p. (in Russian)]

[50] МУ 36.22.2002.92. Методические указания по проведению обследования специальных монтажных кранов с истекшими сроками службы с целью определения возможности их дальнейшей эксплуатации. Руководящий документ. М.: ВКТИ МОНТАЖСТРОЙМЕХАНИЗАЦИЯ. 1992. 49 c. [MU 36.22.2002.92. Guidelines for conducting a survey of special installation cranes with expired service lives in order to determine the possibility of their further operation. Guidance document. Moscow: VKTI MONTAZHSTROYMEKHANIZATSIYA. 1992. 49 p. (in Russian)] 